\title{
Predicting Competition Performance in Short Trail Running Races with Lactate Thresholds
}

\author{
by \\ Volker Scheer ${ }^{1,2,3}$, Solveig Vieluf', Tanja I Janssen³, Hans-Christian Heitkamp
}

Trail running is a popular sport, yet factors related to performance are still not fully understood. Lactate thresholds have been thoroughly investigated in road running and correlate strongly with race performance, but to date few data are available about the value in trail running performance prediction. We examined 25 trail runners (age 31.2 \pm 5.1 years, BMI $\left.22.2 \pm 1.82 \mathrm{~kg} / \mathrm{m}^{2}\right)$ with an initial graded exercise test for measurement of $\mathrm{VO}_{2 \max }\left(59.5 \pm 5.2 \mathrm{ml} \cdot \mathrm{kg}^{-1} \cdot \mathrm{min}^{-}\right.$ 1) and lactate thresholds (LT): LTAET (LT aerobic) $1.03 \pm 0.59 \mathrm{mmol} / \mathrm{l} ; 11.2 \pm 1.1 \mathrm{~km} / \mathrm{h}$ ), IAT (individual lactate threshold) $(2.53 \pm 0.59 \mathrm{mmol} / \mathrm{l} ; 15.4 \pm 1.6 \mathrm{~km} / \mathrm{h})$ and LT4 (lactate threshold at $4 \mathrm{mmol} / \mathrm{ll})(16.2 \pm 1.9 \mathrm{~km} / \mathrm{h})$. All runners subsequently participated in a $31.1 \mathrm{~km}$ XS trail race and 9 runners in a $21 \mathrm{~km}$ XXS trail race. Race performance times correlated negatively with the XS trail run (LTAET: $r=-0.65, p<0.01$; LT4: $r=-0.87, p<0.01$; IAT: $r=-0.84, p<0.01$ ) and regression analysis showed that race performance could be predicted by: $L T 4:-324.15 \times L T 4+13195.23\left(R^{2}=.753, F_{1,23}\right.$ $=70.02, p<0.01)$. A subgroup analysis showed higher correlations with race performance for slower than faster runners. No correlations were found with the XXS race. Lactate thresholds can be of value in predicting trail race performance and help in designing training plans.

Key words: anaerobic threshold, exercise test, exercise, endurance, athletic performance.

\section{Introduction}

Trail running is attracting a growing number of participants, especially in ultraendurance distances and even among children (Scheer, 2019; Scheer and Hoffman, 2018). It is defined by the International Trail Running Association (ITRA) as a pedestrian foot race in natural environment (mountain, desert, forest, plain) with less than $20 \%$ of the race course on paved or asphalt roads (ITRA, 2018). Trail running has been recognised by the International Association of Athletics Federation (IAAF) as a separate sport discipline and races are classified in seven different categories depending on the distance and elevation, ranging from short XXS races (up to $24 \mathrm{~km}$ ) to $X X L$ races (in excess of 210 $\mathrm{km})$ (ITRA, 2018) and are often held in challenging environmental conditions. Due to the high and

versatile demands that occur during trail running, it is of great importance that athletes prepare in a targeted and comprehensive way. Medical, nutritional, biochemical and physiological aspects related to trail running preparation and consequences have been well researched (Hoffman et al., 2014; Millet and Millet, 2012). However, data on performance predictions in trail running are still relatively scarce (Balducci et al., 2017; Ehrström et al., 2017; Fornasiero et al., 2017; Scheer et al., 2018a) and this may partly be due to the complexity of trail running with its prolonged uphill and downhill running sections, over uneven terrain, placing different physiological and biomechanical demands on the musculature and the human body compared to road running (Degache et al., 2013; Giandolini et al., 2016;

\footnotetext{
1 - Ultra Sports Science Foundation, Pierre Benite, France.

2 - British Forces Germany, RRU Sennelager, Normandy Barracks, BFPO 16.

3 - Institute of Sports Medicine, Department of Health, University of Paderborn, Paderborn, Germany.
} 
Giovanelli et al., 2016). Lower limb muscular strength and resistance to fatigue are important factors in trail running and have been shown to correlate to performance (Balducci et al., 2017; Ehrström et al., 2017; Fornasiero et al., 2017; Giovanelli et al., 2016; Lazzer et al., 2015).

Anthropometric variables and data on training characteristics are also important factors in predicting race performance, especially in road running (Knechtle et al., 2014, 2011, 2010; O'Loughlin et al., 2019; Rüst et al., 2011; Schmid et al., 2012). Body fat content and running speed during training sessions are particularly useful predictors in half marathon running, both in women and men (Knechtle et al., 2014, 2011; Rüst et al., 2011), whereas in recreational marathon runners body mass, body mass index, various skinfold thicknesses measurements, maximal training distance per week, number of running training sessions per week and running speed during training sessions are important predictors of race time (Schmid et al., 2012). Similar findings have been observed in longer running distances such as ultramarathon running (Knechtle et al., 2010; O'Loughlin et al., 2019).

Physiological variables such as maximal oxygen uptake $\left(\mathrm{VO}_{2 \max }\right)$ (Ehrström et al., 2017; Fornasiero et al., 2017; Giovanelli et al., 2016) and running economy (RE) are important factors in predicting trail race performance (Lazzer et al., 2015; Scheer et al., 2018c; Vernillo et al., 2015). In endurance running, performance prediction is well established and the classical model has been accepted widely including variables such as $\mathrm{VO}_{2 \max }$, percentage of $\mathrm{VO}_{2 \max } \quad\left(\% \mathrm{VO}_{2 \max }\right)$, ventilatory thresholds (VT) and running economy (RE) (Barnes and Kilding, 2015; Larsen, 2003). However, in a short trail running race this classical model was only able to predict $48 \%$ of race performances (Ehrström et al., 2017). Another study investigated $\mathrm{VO}_{2 \max }$, submaximal running intensities and previous year's race performance and this model predicted $99 \%$ of a short trail running race performance (Scheer et al., 2018a). However, numerous different laboratory tests need to be performed to reach those predictive numbers, thus applying only one physiological test or marker to predict performance may be of benefit.

Lactate thresholds (LT) are classical performance predictors, especially in road running and cycling (Faude et al., 2009). It is widely accepted that LTs are a measure for aerobic endurance performance and the relationship of lactate thresholds (LTs) with competitive performance is well established (Faude et al., 2009). Furthermore, the concept of aerobic-anaerobic transition is important for training prescription (Kindermann et al., 1979). Lactate concentrations have been measured since the 1960s when the enzymatic method for measuring lactate concentrations from capillary blood samples was developed (Faude et al., 2009). Research has mainly focused on LT concepts in road running, which have been shown to correlate strongly to race performance (Faude et al., 2009; Sales et al., 2017; Svedahl and MacIntosh, 2003), but to date little is known about LT and performance prediction in trail running (Scheer et al., 2018a).

Our aim was to examine established LT concepts (fixed and individual LT) in a group of trail runners and evaluating them in two different short trail running competitions, gaining further insight into the value of classical performance predictors in trail running. Our hypothesis was that LT would correlate with performance in a short trail running race and that we would be able to predict race performance.

\section{Methods}

\section{Participants}

Twenty-five trail runners from local running clubs participated in this study. They were recruited through announcements at local running clubs and local Internet groups for runners. Only healthy, male trail runners, between the ages of 1840 years, were allowed to participate. Runners were defined as trail runners when they completed the majority of their training on trail surfaces and / or had previously participated in trail running competitions as defined by ITRA. Some athletes participated very successfully in local and regional competitions, but none of them were part of the national team or at top level in the ITRA performance ranking. Female runners, runners with concurrent health issues or injuries or not within the age range set ( $<18$ or $>40$ years) were not allowed to participate in the current study. All athletes were informed of the protocol prior to the first test and provided written, informed consent to participate. The internal review board of the Ärztekammer Westfalen-Lippe and the 
Westfälische Wilhelms Universität, Münster, Germany, approved all procedures and research was conducted according to international ethical standards (Harriss and Atkinson, 2015).

\section{Design and Procedures}

All runners were healthy, without current injuries and familiar with treadmill running. They completed a graded incremental exercise test (step test) for lactate measurements and indirect calorimetry on the treadmill. The step test was preceded by a $3 \mathrm{~min}$ warm up at $6.0 \mathrm{~km} / \mathrm{h}$ and then started at a speed of $8.0 \mathrm{~km} / \mathrm{h}$, with increases of 2.0 $\mathrm{km} / \mathrm{h}$ every $3 \mathrm{~min}$ until task failure (Scheer et al., 2018b). The treadmill slope was 1.0\% (Jones and Doust, 1996). After each step capillary blood lactate (bLa) measurements were taken. Capillary blood was drawn from the right ear lobe, and filled into a plastic capillary end to end tube. This was done at rest, after each step and at termination of the exercise test. Samples were analyzed with Biosen S-line (EKF diagnostics, Barleben, Germany). The aerobic lactate threshold (LTAER) was defined as the point at which blood lactate (bLA) began to rise above baseline levels (Kindermann et al., 1979). Anaerobic lactate thresholds (LTAN) were obtained as individual and fixed thresholds. The individual anaerobic threshold was defined as the running speed at a net increase in lactate concentration of $1.5 \mathrm{mmol} / \mathrm{l}$ above the lactate concentration at the aerobic lactate threshold (Roecker et al., 1998). The fixed LTAN was obtained at a speed of $4 \mathrm{mmol} / \mathrm{l}$ (LT4) (Faude et al., 2009). The lactate curve was obtained using the lactate software program Ergonizer (Ergonizer, Software für sportmedizinische Leistungsdiagnostik, K. Röcker, Freiburg, Germany).

Continuous measurements of ventilatory variables and oxygen uptake were performed with a breath by breath gas and volume analyzer (Metalyzer 3B, Cortex Biophysik, Leipzig, Germany). $\mathrm{VO}_{2 \max }$ values were accepted either in the presence of a plateau in oxygen uptake or attainment of established secondary criteria (Howley et al., 1995). The heart rate was obtained via bluetooth (Cardio 100 BT, Custo med., Ottobrunn, Germany) and the treadmill used was $\mathrm{h} / \mathrm{p} /$ cosmos Pulsar 3p (Traunstein, Germany). The RPE was measured using the 6-20 point Borg scale immediately at the end of each test (Borg, 1985).

All exercise tests took place within 1-6 weeks of the trail race competition and the races took place four weeks apart. All runners completed a local trail running competition, classified as an XS trail race according to the ITRA category (Hermannslauf $31 \mathrm{~km}$ trail race, positive elevation $515 \mathrm{~m}$, negative elevation $710 \mathrm{~m}$; www.hermannslauf.de). Nine runners additionally completed an XXS trail competition according to the ITRA category (Luisenturmlauf $21.1 \mathrm{~km}$, positive elevation $550 \mathrm{~m}$, negative elevation $550 \mathrm{~m}$; www.lcsolbad.de). Finishing times were obtained from official race results through the race websites (www.hermanslauf.de and www.lcsolbad.de).

\section{Statistical Analyses}

Statistical analysis was performed with SPSS for Windows (version 24.0; IBM Corp, Armonk, NY). Descriptive data were reported as means, SD, and 95\% confidence intervals. The Kolmogorov-Smirnov test was used to test for normal distribution. To examine the relationships between selected outcome measures (LTAET, LT4, IAT) and the race results, the Pearson productmoment correlation coefficient (r) with a 95\% confidence interval was calculated. Linear regression analysis was performed to predict the value of race results for either the $\mathrm{XS}$ trail races from laboratory outcome measure LT4. Effect sizes for correlations are given in $r$ and for regression analysis in $\mathrm{R}^{2}$. Statistical significance was set at $p<$ 0.05 for all analysis.

\section{Results}

Basic data, anthropometric measurements and training history from participants are presented in Table 1. Results from the graded incremental exercise test are shown in Table 2. Race results for the $31 \mathrm{~km} \mathrm{XS}$ trail race were $02 \mathrm{~h} 12 \mathrm{~min}$ $24 \mathrm{~s} \pm 00 \mathrm{~h} 12 \mathrm{~min} 01 \mathrm{~s}$. The subgroup of 9 runners competing in both trail runs completed the $\mathrm{XS}$ race in $02 \mathrm{~h} 14 \mathrm{~min} 40 \mathrm{~s} \pm 00 \mathrm{~h} 09 \mathrm{~min} 47 \mathrm{~s}$ and the XXS trail race of $21.1 \mathrm{~km}$ in $01 \mathrm{~h} 27 \mathrm{~min} 33 \mathrm{~s} \pm 00 \mathrm{~h} 06$ min 52 s. Performance values did not correlate for both runs within the group of 9 runners that finished both races $(r=0.45 ; p=0.23)$.

Figure 1 shows the correlation between LTAET, LT4 and IAT with race results for the XS trail race.

Correlating the race performance times with the selected test measures showed that speeds at LTAET, LT4 and IAT correlated negatively with 
the XS trail run (LTAET: $\mathrm{r}=-0.65, p<0.01$; LT4: $\mathrm{r}=$ $-0.87, p<0.01$; IAT: $\mathrm{r}=-0.84, p<0.01)$, but not with the XXS trail run (LTAET: $\mathrm{r}=-0.26, p=0.50$; LT4: $\mathrm{r}$ $=-0.32, p=0.40$; IAT: $\mathrm{r}=-0.39, p=0.30)$. This means the higher the speed at the thresholds, the better the XS race performance. Similarly, regression analysis showed that race performance could be predicted by the LT4: $-324.15 \times \mathrm{LT} 4+13195.23\left(\mathrm{R}^{2}=\right.$ $\left..753, \mathrm{~F}_{1,23}=70.02, p<0.01\right)$.
A subgroup analysis between faster and slower runners (XS trail race $<02 \mathrm{~h} 10 \mathrm{~min}$ and $>2$ h $10 \mathrm{~min}$ ) correlating LTAET, LT4 and IAT to the race time is presented in Figure 1. Correlations are higher for slower (LTAET: $\mathrm{r}=-0.49, p=0.07$; LT4: $\mathrm{r}$ $=-0.78, p<0.01$; IAT: $\mathrm{r}=-0.78, p<0.01)$ than for faster runners (LTAET: $\mathrm{r}=-0.17, p=0.63$; LT4: $\mathrm{r}=$ $0.65, p=0.03$; IAT: $\mathrm{r}=-0.58, p=0.06$ ) (Figure 1 ).
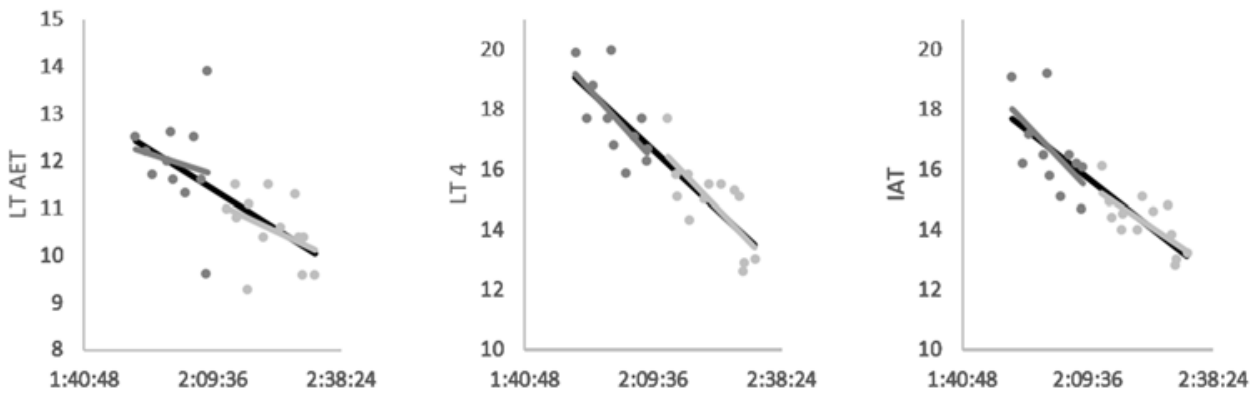

Figure 1

Correlations between race results for the XS trail race and laboratory measures (in $\mathrm{km} / \mathrm{h}$ ) for the slow (light grey) and fast (dark grey) runners, as well as the overall group (black) (LTAET - aerobic lactate threshold, LT4 - lactate threshold at $4 \mathrm{mmol} / \mathrm{l}$, IATindividual lactate threshold).

Table 1

Participants' characteristics as means, standard deviations (SD) and lower and upper confidence intervals (CI) per group.

\begin{tabular}{|c|c|c|c|c|}
\hline Variables & Mean & SD & $\begin{array}{l}\text { Lower } 95 \% \\
\text { CI }\end{array}$ & $\begin{array}{l}\text { Upper } 95 \% \\
\text { CI }\end{array}$ \\
\hline Age & 31.23 & 5.12 & 28.96 & 33.12 \\
\hline Body mass (kg) & 72.72 & 8.73 & 69.11 & 76.32 \\
\hline Height $(\mathrm{cm})$ & 180.98 & 7.21 & 178.00 & 183.96 \\
\hline $\mathrm{BMI}\left(\mathrm{kg} / \mathrm{m}^{2}\right)$ & 22.20 & 1.82 & 21.39 & 22.94 \\
\hline $\begin{array}{l}\text { Training time/week } \\
\text { (h) a) }\end{array}$ & 4.96 & 1.47 & 4.34 & 5.58 \\
\hline $\begin{array}{l}\text { Weekly running } \\
\text { distance }(\mathrm{km})^{\text {a) }}\end{array}$ & 77.27 & 28.74 & 65.13 & 89.41 \\
\hline Years of runningb) & 7.10 & 5.37 & 4.65 & 9.53 \\
\hline Best time 10 km b) & 00:34:32 & 00:08:09 & 00:30:49 & 00:38:15 \\
\hline $\begin{array}{l}\text { Best half marathon } \\
\text { time a) }\end{array}$ & 01:11:04 & 00:28:06 & 00:59:12 & $01: 22: 56$ \\
\hline
\end{tabular}

a) data from 24 runners; ${ }^{b}$ data from 21 runners 
Table 2

Overview of laboratory test outcomes as means, standard deviations (SD) and lower and upper confidence intervals (CI) per group.

\begin{tabular}{lccccc}
\hline Variables & Mean & SD & Lower 95\% CI & Upper 95\% CI \\
\hline $\mathrm{VO}_{2 \max }\left(\mathrm{ml}_{\mathrm{kg}} \mathrm{k}^{-1} \mathrm{~min}^{-1}\right)$ & 59.48 & 5.17 & 57.34 & 61.62 \\
vVO2max $(\mathrm{km} / \mathrm{h})$ & 19.42 & 1.66 & 18.74 & 20.10 \\
Max. heart rate (HR) (b/min) & 185.28 & 10.26 & 181.04 & 189.21 \\
RER & 1.28 & 0.07 & 1.25 & 1.31 \\
RPE (Borg) & 18.92 & 1.00 & 18.51 & 19.33 \\
Lactate rest (mmol/l) & 0.84 & 0.30 & 0.72 & 0.97 \\
Lactate end (mmol/l) & 9.96 & 2.29 & 9.01 & 10.90 \\
Lactate 3 min post exercise & 10.55 & 2.55 & 9.50 & 11.61 \\
LTAET (mmol/l) & 1.03 & 0.59 & 0.78 & 1.27 \\
LTAET (km/h) & 11.22 & 1.10 & 10.76 & 11.67 \\
LTAET HR (b/min) & 140.76 & 12.08 & 135.77 & 145.58 \\
IAT (mmol/l) & 2.53 & 0.59 & 2.28 & 2.78 \\
IAT (km/h) & 15.35 & 1.63 & 14.67 & 16.02 \\
IAT HR (b/min) & 168.72 & 9.95 & 164.61 & 172.83 \\
LT4 (km/h) & 16.20 & 1.93 & 15.40 & 17.00 \\
LT4 HR (b/min) & 173.24 & 9.17 & 169.46 & 177.02 \\
\hline
\end{tabular}

\section{Discussion}

The aim of the present study was to examine LT concepts in a group of trail runners and to evaluate their value for predicting performance in trail running. The main findings of our study were that LT correlated with race performance times in a short trail running competition and that race performance could be predicted with greater precision in slower compared to faster runners. This is in line with our hypothesis that LT are of value in predicting short trail running performance.

A number of different LT concepts exist, mainly the LTAET, fixed LT or individual LT
(IAT) concepts (Faude et al., 2009). The obvious gold standard to validate a LT concept is to compare it with recent competition performance in an endurance event or to assess its value in predicting endurance performance in an endurance event (Faude et al., 2009). We measured LT during a graded exercise test and compared race results of two short trail running races to assess its value in performance prediction. Our findings demonstrated that LT4 and IAT correlated best with the XS trail race $(r=0.87$ and $r=0.84$, respectively) while correlation for LTAET was $r=$ 0.65 . The correlation was higher for a subgroup of slower runners compared to faster ones. In road running, 
correlations between LT and running performance vary depending on the race distance investigated and they range between 0.43 and 0.93 in endurance events from $800 \mathrm{~m}$ to $16.1 \mathrm{~km}$ (Faude et al., 2009) and between 0.68 and 0.98 in running distance between 19.3 and $42.2 \mathrm{~km}$ (Farrell et al., 1993; Faude et al., 2009; Roecker et al., 1998; Sjödin and Jacobs, 1981).

Our findings that LT4 and IAT correlated better with race performance than LTAET are similar to previous results in road running where fixed LT and IAT have been shown to be better predictors of race performance between 19.3 and $42.2 \mathrm{~km}$ than LTAET (Föhrenbach et al., 1987; Roecker et al., 1998; Tokmakidis et al., 1998). This is not surprising when considering the concept of aerobic-anaerobic transition as a framework of lactate diagnosis for performance and training prescription in endurance sports (Kindermann et al., 1979). This concept consists of two breakpoints, with a low intensity range at the intensity at which bLa begins to rise above baseline levels (aerobic threshold) and at higher workloads leading to an equilibrium between lactate production and lactate elimination (anaerobic threshold) (Kindermann et al., 1979). Exercise intensities at LTAET can be maintained for long hours (e.g. during ultramarathons) or used as regenerative sessions in high level endurance athletes (Kindermann et al., 1979). Intensities above LTAET result in bLA elevation, but as long as steady state conditions are maintained exercise and can be maintained for prolonged periods of time (Baron et al., 2008). Exercise intensities above the anaerobic threshold can be used for interval training sessions in endurance sports (Faude et al., 2009).

LT4 correlated better for predicting race performance compared to IAT, however, when using those values for designing training plans it needs to be remembered that fixed LT such as LT4 do not take into account considerable interindividual differences and may underestimate (particularly in anaerobically trained subjects) or overestimate (in aerobically trained subjects) real endurance capacity (Faude et al., 2009).

Our results may be of value in the assessment of trail runners as graded incremental exercise tests for the measurements of lactate thresholds are routine in many exercise physiology labs (Scheer et al., 2018a). Training prescription can be tailored according to the aerobic-anaerobic model and training gains observed with continued lactate tests, as a rightward shift of the lactate curve (lower bLa at given workload) can demonstrate improved endurance capacity (Bosquet et al., 2002), whereas a leftward shift can show a worsening endurance capacity (Mujika and Padilla, 2001).

LT have previously only been investigated in a small group of highly trained trail runners, as part of a prediction model comparing various exercise tests, demonstrating the importance of submaximal physiological measurements combined with previous year's race performance of the same trail race, predicting $99 \%$ of a short trail running race (Scheer et al., 2018a). In the current study we examined the importance of lactate thresholds in an XS trail race, where performance can be predicted with the following formula: LT4: $-324.15 \times \mathrm{LT} 4+13195.23\left(\mathrm{R}^{2}=.753, \mathrm{~F}_{1,23}=70.02, p<\right.$ $0.01)$. Performance in a shorter XXS trail race could not be predicted with the available data, possibly due to the specific race characteristics and low, heterogeneous participant numbers.

However, the results from this study demonstrate the importance of LT in trail runners, as it can help predict short trail running performances and can help in prescribing training plans, similarly as has been well documented in road runners. Studies on different trail races (distance and elevation) will help clarify the importance on lactate thresholds in trail running.

From a practical perspective these results are important as this is the first one to demonstrate that LT do not only provide valuable data for race prediction and training in road running, but also in trail running. This is especially useful for the practitioner, since graded exercise tests with the measurements of LT are often routinely used in many exercise physiology labs and coaches, scientist and physicians can draw valuable information from those results.

\section{Limitations}

Lactate levels are known to be influenced by depleted glycogen stores, e.g. low carbohydrate diet or preceding exhaustive exercise (Yoshida, 1986). Athletes were instructed to abstain from exhaustive exercise at least 24 hours prior to the exercise test and none of the athletes were known to engage in low carbohydrate diets. Lactate levels may also be influenced by muscle fibre 
composition, glycolytic and lypolytic enzyme activity, capillary or mitochondrial density (Midgley et al., 2007), but we were not able to assess these factors in our group of athletes. Methodological issues, such as length of step duration of the graded exercise test, anatomical site of lactate blood extraction and methods of lactate analysis have been shown to influence results (Faude et al., 2009), but have been used in a standardized manner by experienced personnel in our laboratory setting. We recognise that other factors are more than likely to influence trail running performance prediction, but the aim of the current study was to evaluate the value and extent of lactate thresholds in predicting performance.

\section{Conclusions}

Lactate thresholds can be of value in predicting trail race performance and aid therefore in designing valuable training plans. Race performance times correlated in $84 \%$ with an XS trail run. A subgroup analysis showed higher correlations with race performance for slower than faster runners.

\section{Acknowledgements}

We thank Julian Brede, Pierre Kirchhoff and Katharina Ramme in helping to collect data during this research project. We thank all trail runners for their participation in the study.

\section{References}

Balducci P, Clémençon M, Trama R, Blache Y, Hautier C. Performance Factors in a Mountain Ultramarathon. Int J Sports Med, 2017; 38: 819-826. https://doi.org/10.1055/s-0043-112342

Barnes KR, Kilding AE. Running economy: measurement, norms, and determining factors. Sports Med Open, 2015; 1: 8. https://doi.org/10.1186/s40798-015-0007-y

Baron B, Noakes TD, Dekerle J, Moullan F, Robin S, Matran R, Pelayo P. Why does exercise terminate at the maximal lactate steady state intensity? $\mathrm{Br} J$ Sports Med, 2008; 42: 828-833. https://doi.org/10.1136/bjsm.2007.040444

Borg G. An introduction to Borg's RPE-scale. Ithaca, NY: Mouvement Publications; 1985

Bosquet L, Léger L, Legros P. Methods to determine aerobic endurance. Sports Med, 2002; 32: 675-700

Degache F, Guex K, Fourchet F, Morin JB, Millet GP, Tomazin K, Millet GY. Changes in running mechanics and spring-mass behaviour induced by a 5-hour hilly running bout. J Sports Sci, 2013; 31: 299-304. https://doi.org/10.1080/02640414.2012.729136

Ehrström S, Tartaruga MP, Easthope CS, Brisswalter J, Morin JB, Vercruyssen F. Short trail running race: beyond the classic model for endurance performance. Med Sci Sports Exerc, 2017; 580-588. https://doi.org/10.1249/MSS.0000000000001467

Farrell PA, Wilmore JH, Coyle EF, Billing JE, Costill DL. Plasma lactate accumulation and distance running performance. Med Sci Sports Exerc, 1979; 25, 1091-1097; discussion 1089-1090

Faude O, Kindermann W, Meyer T. Lactate threshold concepts: how valid are they? Sports Med, 2009; 39: 469490

Föhrenbach R, Mader A, Hollmann W. Determination of endurance capacity and prediction of exercise intensities for training and competition in marathon runners. Int J Sports Med, 1987; 8: 11-18. https://doi.org/10.1055/s-2008-1025633

Fornasiero A, Savoldelli A, Fruet D, Boccia G, Pellegrini B, Schena F. Physiological intensity profile, exercise load and performance predictors of a 65-km mountain ultra-marathon. J Sports Sci, 2017; 1-9. https://doi.org/10.1080/02640414.2017.1374707

Giandolini M, Horvais N, Rossi J, Millet GY, Morin JB, Samozino P. Acute and delayed peripheral and central neuromuscular alterations induced by a short and intense downhill trail run. Scand J Med Sci Sports, 2016; 26: 1321-1333. https://doi.org/10.1111/sms.12583 
Giovanelli N, Taboga P, Rejc E, Simunic B, Antonutto G, Lazzer S. Effects of an Uphill Marathon on Running Mechanics and Lower-Limb Muscle Fatigue. Int J Sports Physiol Perform, 2016; 11: 522-529. https://doi.org/10.1123/ijspp.2014-0602

Harriss DJ, Atkinson G. Ethical Standards in Sport and Exercise Science Research: Update. Int J Sports Med, 2015; 36: 1121-1124. https://doi.org/10.1055/s-0035-1565186

Hoffman MD, Pasternak A, Rogers IR, Khodaee M, Hill JC, Townes DA, Scheer BV, Krabak BJ, Basset P, Lipman GS. Medical services at ultra-endurance foot races in remote environments: medical issues and consensus guidelines. Sports Med, 2014; 44: 1055-1069. https://doi.org/10.1007/s40279-014-0189-3

Howley ET, Bassett DR, Welch HG. Criteria for maximal oxygen uptake: review and commentary. Med Sci Sports Exerc, 1995; 27: 1292-1301

ITRA. International Trail Running Association [WWW Document]. URL www.itra.run (accessed 11.4.18)

Jones AM, Doust JH. A 1\% treadmill grade most accurately reflects the energetic cost of outdoor running. J Sports Sci, 1996; 14: 321-327. https://doi.org/10.1080/02640419608727717

Kindermann W, Simon G, Keul J. The significance of the aerobic-anaerobic transition for the determination of work load intensities during endurance training. Eur J Appl Physiol Occup Physiol, 1979; 42: 25-34

Knechtle B, Barandun U, Knechtle P, Zingg MA, Rosemann T, Rüst CA. Prediction of half-marathon race time in recreational female and male runners. Springerplus, 2014; 3: 248. https://doi.org/10.1186/2193-1801-3248

Knechtle B, Knechtle P, Barandun U, Rosemann T, Lepers R. Predictor variables for half marathon race time in recreational female runners. Clinics (Sao Paulo), 2011; 66: 287-291. https://doi.org/10.1590/s180759322011000200018

Knechtle B, Knechtle P, Rosemann T, Lepers R. Predictor variables for a 100-km race time in male ultramarathoners. Percept Mot Skills, 2010; 111: 681-693. https://doi.org/10.2466/05.25.PMS.111.6.681-693

Larsen HB. Kenyan dominance in distance running. Comp Biochem Physiol, Part A Mol Integr Physiol, 2003; 136: 161-170

Lazzer S, Salvadego D, Taboga P, Rejc E, Giovanelli N, di Prampero PE. Effects of the Etna uphill ultramarathon on energy cost and mechanics of running. Int J Sports Physiol Perform, 2015; 10: 238-247. https://doi.org/10.1123/ijspp.2014-0057

Midgley AW, McNaughton LR, Jones AM. Training to enhance the physiological determinants of longdistance running performance: can valid recommendations be given to runners and coaches based on current scientific knowledge? Sports Med, 2007; 37: 857-880

Millet GP, Millet GY. Ultramarathon is an outstanding model for the study of adaptive responses to extreme load and stress. BMC Med, 2012; 10: 77. https://doi.org/10.1186/1741-7015-10-77

Mujika I, Padilla S. Cardiorespiratory and metabolic characteristics of detraining in humans. Med Sci Sports Exerc, 2001; 33: 413-421

O'Loughlin E, Nikolaidis PT, Rosemann T, Knechtle B. Different Predictor Variables for Women and Men in Ultra-Marathon Running-The Wellington Urban Ultramarathon 2018. Int J Environ Res Public Health, 2019; 16. https://doi.org/10.3390/ijerph16101844

Roecker K, Schotte O, Niess AM, Horstmann T, Dickhuth HH. Predicting competition performance in longdistance running by means of a treadmill test. Med Sci Sports Exerc, 1998; 30: 1552-1557

Rüst CA, Knechtle B, Knechtle P, Barandun U, Lepers R, Rosemann T. Predictor variables for a half marathon race time in recreational male runners. Open Access J Sports Med, 2011; 2: 113-119. https://doi.org/10.2147/OAJSM.S23027

Sales MM, Sousa CV, da Silva Aguiar S, Knechtle B, Nikolaidis PT, Alves PM, Simões HG. An integrative perspective of the anaerobic threshold. Physiol Behav, 2017. https://doi.org/10.1016/j.physbeh.2017.12.015 
Scheer V. Participation Trends of Ultra Endurance Events. Sports Med Arthrosc Rev, 2019; 27: 3-7. https://doi.org/10.1097/JSA.0000000000000198

Scheer V, Hoffman MD. Should Children Be Running Ultramarathons? Current Sports Medicine Reports, 2018; 17: 282. https://doi.org/10.1249/JSR.0000000000000512

Scheer V, Janssen TI, Vieluf S, Heitkamp HC. Predicting Trail Running Performance With Laboratory Exercise Tests and Field Based Results. Int J Sports Physiol Perform, 2018; 1-13. https://doi.org/10.1123/ijspp.20180390

Scheer V, Ramme K, Reinsberger C, Heitkamp HC. VO2max Testing in Trail Runners: Is There a Specific Exercise Test Protocol? Int J Sports Med, 2018; 39: 456-461. https://doi.org/10.1055/a-0577-4851

Scheer V, Vieluf S, Cramer L, Jakobsmeyer R, Heitkamp HC. Changes in Running Economy During a 65-km Ultramarathon. Front Physiol, 2018; 9: 1809. https://doi.org/10.3389/fphys.2018.01809

Schmid W, Knechtle B, Knechtle P, Barandun U, Rüst CA, Rosemann T, Lepers R. Predictor variables for marathon race time in recreational female runners. Asian J Sports Med, 2012; 3: 90-98

Sjödin B, Jacobs I. Onset of blood lactate accumulation and marathon running performance. Int J Sports Med, 1981; 2: 23-26. https://doi.org/10.1055/s-2008-1034579

Svedahl K, MacIntosh BR. Anaerobic threshold: the concept and methods of measurement. Can J Appl Physiol, 2003; 28: 299-323

Tokmakidis SP, Léger LA, Pilianidis TC. Failure to obtain a unique threshold on the blood lactate concentration curve during exercise. Eur J Appl Physiol Occup Physiol, 1998; 77: 333-342. https://doi.org/10.1007/s004210050342

Vernillo G, Savoldelli A, Zignoli A, Skafidas S, Fornasiero A, La Torre A, Bortolan L, Pellegrini B, Schena F. Energy cost and kinematics of level, uphill and downhill running: fatigue-induced changes after a mountain ultramarathon. J Sports Sci, 2015; 33: 1998-2005. https://doi.org/10.1080/02640414.2015.1022870

Yoshida T. Effect of dietary modifications on anaerobic threshold. Sports Med, 1986; 3: 4-9

\section{Corresponding author:}

\section{Volker Scheer}

British Forces Germany, RRU Sennelager,

Normandy Barracks, BFPO 16,

Tel. 004952549822329

E-mail: volkerscheer@doctors.org.uk 